\title{
There is much to be learnt about the costs of multiple sclerosis in Latin America
}

\author{
Hay mucho a ser aprendido sobre los costos de la esclerosis múltiple en América Latina \\ Marina Romano', Gerardo Machnicki², Juan Ignacio Rojas ${ }^{3}$, Nadina Frider ${ }^{4}$, Jorge Correale ${ }^{5}$
}

\begin{abstract}
We assessed the health economic data of multiple sclerosis (MS) in Latin America (LA). Method: A systematic review of the literature from 1990 to 2011 was conducted. Outcome measures included: mean cost of disease modifying therapies (DMTs), mean cost of treatment of relapses and mean cost of disease by stage stratification measured by the expanded disability status scale (EDSS). Results: Seven studies from three countries (Brazil, Argentina and Colombia) were included. In 2004, in Argentina, the mean cost of DMT treatment was reported to be USD 35,000 per patient treated. In Brazil, the total MS expenditure of DMTs rose from USD 14,011,700 in 2006 to USD 122,575,000 in 2009. Patient costs ranged between USD 10,543 (EDSS 8-9.5) and USD 25,713 (EDSS 3-5.5). Indirect costs markedly increased for the EDSS 8-9.5 patients. Conclusion: Further research assessing the economic burden of MS in LA is warranted.
\end{abstract}

Key words: multiple sclerosis; Latin America; costs; cost analysis.

\section{RESUMEN}

Evaluamos los costos de la esclerosis múltiple (EM) en América Latina (AL). Métodos: Revisión sistemática de la literatura desde 1990 hasta 2011. Los resultados evaluados fueron: coste medio de los tratamientos modificadores de la enfermedad (DMTs), coste medio del tratamiento de las recaídas y la media de coste de la enfermedad estratificado por la Expanded Disability Status Scale (EDSS). Resultados: Siete estudios de tres países (Brasil, Argentina y Colombia) fueron incluidos. El costo promedio del tratamiento de DMTs fue de USD 35.000 por paciente para el año 2004 en Argentina y el total del costo de los DMTs aumentó de USD 14.011,700 en 2006 a USD 122.575,000 en Brasil en 2009. Los costos de pacientes oscilaron entre USD 10.543 (EDSS 8-9.5) y USD 25.713 (EDSS 3.5 a 5). Los costes indirectos aumentaron para la EDSS mayor discapacidad (EDSS 8-9.5). Conclusión: Estudios adicionales del costo de la EM en AL son necesarios..

Palabras-Clave: esclerosis múltiple, América Latina, costos.

Multiple sclerosis (MS) is the second most common cause of neurological disability in working-age adults, after car accidents, comprising the patient's quality of life, social activities and the environment of the affected patient ${ }^{1}$.

The course of the disease is highly variable, but it is most typically characterised by a relapsing pattern of acute exacerbations followed by periods of remission [relapsingremitting MS (RRMS)]. However, in up to $50 \%$ of the patients, this pattern evolves into a progressive course in which the clinical conditions slowly deteriorate over a period of years [secondary progressive MS (SPMS) $]^{2}$.

Considering this, the economic consequences come predominantly from the early loss of work capacity due to the development of physical disability, the impact of fatigue, the requirements of repeated hospitalisations during disease exacerbations and the need for assistance in

'Centro de Educación Médica e Investigaciones Clínicas (CEMIC), 'Norberto Quirno', Argentina;

${ }^{2}$ Global Health Economics and Outcomes Research, Novartis, Latin America and Canada;

${ }^{3}$ Neurology Department, MS Clinic, Hospital Italiano de Buenos Aires, Argentina;

${ }^{4}$ Novartis Regional Medical Director in Neuroscience, Latin America and Canada;

${ }^{5}$ Department of Neurology, Institute for Neurological Research (FLENI), Argentina

Correspondence: Gerardo Machnicki; Global Health Economics and Outcomes Research, Novartis, Latin America and Canada; Ramallo $1851 ; 1429$ Buenos

Aires, Argentina; E-mail: gerardo.machnicki@novartis.com

Support: This research was supported by a grant from Novartis, Argentina.

Conflict of interest: M Romano has received honoraria for his scientific work from Novartis, Latin America and Canada. G Machnicki is working at Novartis as the Director for Health Economics and Outcomes Research, Latin America and Canada. JI Rojas has received honoraria as a scientific advisor from Novartis, Argentina. Jl Rojas has also received grants to assist in the international congress from Novartis, Argentina and Merck- Serono, Argentina. N Frider is working at the Novartis Regional Office as a Medical Director for Neuroscience for Latin America and Canada. J Correale is a board member at Merck-Serono, Argentina; Novartis, Argentina; Biogen-Idec, Latin America and Merck-Serono, Latin America. Dr Correale has received reimbursement for developing educational presentations for Merck-Serono, Argentina and Latin America; Biogen-Idec, Argentina and TEVA-Tuteur, Argentina, as well as professional travel accommodation stipends.

Received 04 December 2012; Received in final form 27 March 2013; Accepted 03 April 2013. 
daily life activities ${ }^{3,4}$. Disease-modifying therapies (DMTs) were introduced in clinical practice in 1990 to reduce the frequency of relapses, slow disease progression and diminish disability in patients with $\mathrm{MS}^{5-10}$. However, treatment options are particularly limited once the patients reach the SPMS stage. Although DMTs increase the direct costs of the disease, these costs are also offset since the use of DMTs reduces the frequency of relapses, days of hospitalisation, use of symptomatic treatments and the time of rehabilitation, making the final impact on the cost of the disease to be favourable. The mean total lifetime cost per patient of MS in the US was estimated to be USD 2.5 million in $1994^{11,12}$.

Several publications have addressed the epidemiology and costs of MS throughout the world ${ }^{4,13-17}$. Nonetheless, our current knowledge of MS epidemiology and economic burden comes from North American and European studies ${ }^{15,16,18,19}$. Scant data have been published from Latin America (LA) and the Caribbean (SA) ${ }^{15,20-24}$. Thus, it is important to quantify the costs of MS in LA to better understand the impact of the disease on national health systems in the region ${ }^{16,19,21,24,25}$.

Considering this, the aim of the present study was to perform a systematic review (SR) of the health economic data of MS in LA, including costs of hospitalisation, pharmacy data and outpatient as well as inpatient costs.

\section{METHODS}

\section{Search strategy and selection criteria}

We conducted a systematic, non-restricted, language search from January 1990 to September 2011 using electronic databases included in the Cochrane CENTRAL and specialised registers of the Cochrane Multiple Sclerosis Group, MEDLINE, EMBASE and LILACS. Regional databases, generic and academic internet searches, meta-search engines and databases containing regional proceedings or congresses' annals and doctoral theses, were also looked up. We consulted web sites from the main regional medical societies, experts and associations related to the topic. An annotated search strategy for grey literature was included to retrieve information from relevant sources like regional Ministries of Health, Pan American Health Organization and reports from hospitals following the MOOSE guidelines and the PRISMA statement for the reporting of SRs and meta-analyses ${ }^{26,27}$.

Outcome measures included mean cost of treatment of relapses (steroids and hospitalisation), mean cost of DMTs (by drug) and mean cost of disease by stage stratification measured by the expanded disability status scale (EDSS). Other outcomes searched were mean cost of rehabilitation and health-related patient's quality of life (QoL) and proxy of the patient's QoL (caregiver reported QoL for the patients).
The authors of the selected articles were contacted to obtain missing or additional information when considered necessary. Types of studies included cohort studies, casecontrolled studies, cross-sectional studies and case-series; data considering the outcomes previously described should have been provided in these studies. Randomised, controlled and quasi-randomised, controlled trials were included if they provided cost data for analysis.

\section{Screening and data abstraction}

Two reviewers independently pre-screened the titles and abstracts of all identified citations, and potentially eligible studies were selected. Two reviewers independently assessed the abstract and the full-text versions of all potentially eligible articles to verify the inclusion criteria. Any discrepancies were resolved by consensus in both phases.

Data were abstracted using a previously piloted electronic chart.

\section{Assessment of risk of bias}

Two reviewers independently evaluated the quality of the methodology used in studies included in the SR. The risk of bias of observational studies was assessed by a modified checklist available in Strengthening the Reporting of Observational studies in Epidemiology and in the study conducted by Fowkes and Fulton ${ }^{29}$. We prepared a summary of risk of bias considering six criteria (methods for selecting study participants, methods for measuring exposure and outcome variables, methods to control confounding, design-specific sources of bias and comparability among groups, statistical methods and declaration of conflict of interest). Once again, disagreements were resolved by consensus. The assessment of risk of bias is included in Table 1 .

\section{Analyses}

Included studies were analysed and abstracted to perform the review. All the abstracted data were entered into a computer database, and data from the two reviewers were compared and reconciled. The data has been presented in Table 2.

\section{RESULTS}

Nine hundred and thirty nine citations were identified. After reviewing the titles and abstracts, 830 references were excluded and 108 studies were considered eligible. From those 108 studies, 7 studies met the inclusion criteria after full-text review and were included for data extrac-

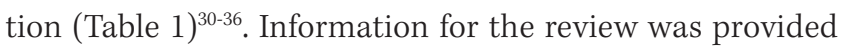
from three countries (Brazil, Argentina and Colombia). Main characteristics of included studies are shown in Tables 1 and 2 . 
Only two studies were published as full texts ${ }^{33,34}$ and the other five studies were presented as abstracts in regional meetings ${ }^{30-32,35,36}$.

The studies were heterogeneous in many aspects including objectives, outcomes and sources of information. The investigators used mainly patient records and/or health insurance chart reviews as their data sources. Some used a single data source, while others used a combination (Table 2).

The first study identified that addressed cost-effectiveness was conducted in Argentina by Gonorazky ${ }^{33}$. The study aimed to evaluate the cost/efficacy ratio of DMTs [interferon beta (IFN $\beta$ ) and glatiramer acetate (GA)] in Argentina, in RRMS, and to compare this information with data from the USA and UK. The estimated yearly costs of treatment of RRMS (in 2004) were as follows: GA, USD 35,280; IFN $\beta 1 b$, USD 31,548; IFN $\beta 1$ a, USD 43,080 (44 mcg, three times a week) and IFN $\beta 1$ a, USD 29,256 (30 mcg, once a week). When the cost efficacy ratio was compared with USA and UK, prices of IFN and GA in Argentina exceeded by $89 \%$ and 191\%, respectively $^{33}$. The source of pharmacy data was taken from the market and it possibly overestimated the cost of DMTs. Other healthcare or societal costs were not considered.

The three studies that addressed DMT use, direct costs and some adherence of MS patients were performed in Brazil $^{32,35,36}$. Two studies determined the distribution of MS-specific treatments in the Brazilian Public Healthcare System and the public pharmaceutical expenditures in MS patients in Brazil during 2006-2009. Both studies used a longitudinal analysis of Brazilian MS pharmacy claims as reported in the Brazilian Ambulatory Information System Database, which included aggregate data from 27 Brazilian states, observed annually. These results are shown in Table 2. The total MS expenditure in DMTs (including all Brazilian states included in the analysis) was USD 14 million for 2006 compared with USD 123 million for 2009. The total investment in MS drugs during 2006 to 2009 was USD 360 million.

Bueno, Godoy and Suzuki ${ }^{35}$ performed a cross-sectional study in Sao Paulo, Brazil to evaluate the medication used by MS patients, costs and the patient's adherence to DMT treatment using the database of the Ministry of Health, called Datasus. The study retrieved information from January to December 2007. The results showed that DMTs accounted for $12.9 \%$ of high cost medications supplied by the public sector in Brazil. An average of $34.4 \%$ of patients adhered to the DMT treatment during the study period; the treatment options in Sao Paulo were distributed as follows: $61 \%$ for IFN $\beta 1$ a subcutaneous (SC) or intramuscular (IM), $21 \%$ for IFN $\beta 1 \mathrm{~b}$ and $19 \%$ for GA. Adherence to DMT was almost 37\% for GA, 34\% for IFN $\beta 1 \mathrm{a}$ (IM/SC) and $32 \%$ for IFN $\beta 1 \mathrm{~b}$. When considering the level of adherence, the annual cost per patient treated was USD 27,824 for GA, USD 42,151 for IFN $\beta$ (SC/IM) and USD 34,038 for IFN $\beta 1 b$. The total treatment cost estimated for that year was USD 92 million.
In another study, Ferreira da Silva et al. ${ }^{36}$ performed a cross-sectional study in Sao Paulo, Brazil that focused on coverage of DMT treatment in MS patients. It was reported that the number of patients on DMT treatment in 2009 in the Sao Paulo region was 1319 patients, resulting in a prevalence of 11.9 cases per 100,000 inhabitants of RRMS patients. Considering this population, the cost for 2009 for the city of Sao Paulo was USD 23 million.

Another Brazilian study performed by Takemoto, Takemoto and Fernandes ${ }^{32}$ aimed to determine the utilisation of health resources among MS patients in the public healthcare system. The analysis considered diagnosis of admission to the hospital, length of hospitalisation, mean length of stay (in days) in the intensive care unit, in-hospital mortality and mean cost per hospitalisation of MS patients. For data collection, researchers performed a longitudinal analysis of Brazilian MS pharmacy claims as reported in the Brazilian Ambulatory Information System Database for the period 2006-2009. The study observed, on average, 1936 hospitalisations due to MS per year (91\% of hospitalisations were for RRMS), the main reason for admission being relapses of MS (90\%). The mean length of hospitalisation was 8.9 days per admission for all MS-related hospitalisations (due to relapse of the disease,) and 7.7 days for those that managed indications other than the relapse of MS, such as infections or management of symptoms. The mean mortality rate was $2.5 \%$ per year. The average cost per hospitalisation was USD 386 for 2009. The total expenditure with MS inpatient admission was USD 651,977 for 2009 (0.53\% of pharmaceutical expenditures due to MS).

A comprehensive cost-study between 2003 and 2008, from a third party payer's perspective and including MS patients from three MS centres in the country, was conducted by Romero et al. ${ }^{34}$ in Colombia. The study estimated direct and indirect costs according to the states of the disease (remissions and relapses, ) and level of progression of the disease (EDSS) ${ }^{37}$. The disease was segmented into four categories according to EDSS (category 1: EDSS 0 to 2.5, category 2: EDSS 3 to 5.5, category 3: EDSS of 6 to 7.5 and category 4 : EDSS 8 to 9.5 ) and the costs pertaining to each category were calculated. The study showed that the mean annual cost per patient varied across disease categories, with the highest cost in category 2 (USD 25,713) and the lowest cost in category 4 (USD 10,543). The cost of DMTs represented $91.5 \%$ of the mean total annual cost of categories 1, 2 and 3. Fifty-eight percentage of the population was treated with DMTs. Indirect costs were minimal, except for category 4, where increases in costs of DMT were offset by reduced usage of DMTs. This is the only identified study which estimated the direct and some of the indirect costs and clearly showed how costs increase with progression of the disease. All the results are shown in Table 2. 
Table 1. Studies included for costs of multiple sclerosis in Latin America.

\begin{tabular}{|c|c|c|c|c|c|}
\hline Studies & Design & Country & City & Outcomes & Risk of bias \\
\hline Bueno, Godoy and Suzuki ${ }^{35}$ & $\begin{array}{l}\text { Design: } \\
\text { Cross-sectional } \\
\text { Setting: } \\
\text { University } \\
\text { Ministry of Health }\end{array}$ & Brazil & Sao Paulo & Costs & High \\
\hline Ferreira da Silva et al. ${ }^{36}$ & $\begin{array}{l}\text { Design: } \\
\text { Cross-sectional } \\
\text { Setting: } \\
\text { Brazil Public System Database }\end{array}$ & Brazil & Sao Paulo & Costs & High \\
\hline $\begin{array}{l}\text { Takemoto, Takemoto } \\
\text { and Fernandes }\end{array}$ & $\begin{array}{l}\text { Design: } \\
\text { Cohort-study } \\
\text { Setting: } \\
\text { Brazilian Ambulatory Information } \\
\text { System Database }\end{array}$ & Brazil & Rio de Janeiro & Costs & High \\
\hline $\begin{array}{l}\text { Takemoto, Takemoto } \\
\text { and Fernandes }\end{array}$ & $\begin{array}{l}\text { Design: } \\
\text { Cohort-study } \\
\text { Setting: } \\
\text { Brazilian Ambulatory Information } \\
\text { System Database }\end{array}$ & Brazil & 27 states & Costs & High \\
\hline Gonorazky $^{33}$ & $\begin{array}{l}\text { Design: } \\
\text { Cross-sectional } \\
\text { Setting: } \\
\text { Cost benefit analysis }\end{array}$ & Argentina & & Costs & Medium \\
\hline Romero et al. ${ }^{34}$ & $\begin{array}{l}\text { Design: } \\
\text { Cohort-study } \\
\text { Setting: Colombian ambulatory } \\
\text { information system }\end{array}$ & Colombia & & Costs & Low \\
\hline
\end{tabular}

Table 2. Studies included and their respective outcomes.

\begin{tabular}{|c|c|c|c|c|}
\hline Study & Year & $\begin{array}{l}\text { City/ } \\
\text { Country }\end{array}$ & Outcomes evaluated & Results/Comments \\
\hline $\begin{array}{l}\text { Bueno, Godoy } \\
\text { and Suzuki }{ }^{35}\end{array}$ & 2007 & $\begin{array}{l}\text { Sao Paulo/ } \\
\text { Brazil }\end{array}$ & $\begin{array}{l}\text {-DMD used in Sao Paulo } \\
\text {-Adherence to DMD in Sao Paulo } \\
\text {-Treatment cost of DMD }\end{array}$ & $\begin{array}{l}\text { Total adherence } 34.4 \% \\
\text {-Treatment distribution: IFN-1a (two brands) 60.66\%, } \\
\text { IFN-1b } \\
20.5 \% \text { and GA } 18.85 \% \\
\text {-Adherence per treatment: GA 36.9\%, IFN-1a (two } \\
\text { brands) 33.67\% and IFN-1b 32.3\% } \\
\text {-Annual costs per patient treated was USD 27,824 } \\
\text { for GA, USD 42,151 for IFN-1a (two brands) and USD } \\
\text { 34,038 for IFN-1b } \\
\text {-Total treatment costs higher than USD } 92 \text { million } \\
\text { per year }\end{array}$ \\
\hline $\begin{array}{l}\text { Ferreira da Silva } \\
\text { et al. }{ }^{36}\end{array}$ & 2009 & $\begin{array}{l}\text { Sao Paulo } \\
\text { /Brazil }\end{array}$ & $\begin{array}{l}\text {-Currently treated MS cases for Sao } \\
\text { Paulo } \\
\text {-Total cost of currently treated MS } \\
\text { cases for Sao Paulo }\end{array}$ & $\begin{array}{l}\text {-1319 patients under treatment } \\
\text {-Prevalence of } 11.9 \text { cases per 100,000 inhabitants of } \\
\text { RRMS cases treated } \\
\text {-Actual costs of all patients treated in Sao Paulo for } \\
2009 \text { was USD } 23,433,100\end{array}$ \\
\hline $\begin{array}{l}\text { Takemoto, } \\
\text { Takemoto and } \\
\text { Fernandes } \\
0-32\end{array}$ & $2006-2009$ & $\begin{array}{l}\text { Rio de } \\
\text { Janeiro/ } \\
\text { Brazil }\end{array}$ & $\begin{array}{l}\text {-Causes of admission to hospital for } \\
\text { MS patients } \\
\text {-Length of hospitalisation of MS } \\
\text { patients } \\
\text {-Mean intensive care unit days of } \\
\text { MS patients } \\
\text {-In-hospital mortality } \\
\text {-Mean cost per hospitalisation }\end{array}$ & $\begin{array}{l}\text {-Annual hospitalisations due to MS were } 1936 \text { epi- } \\
\text { sodes, per year } \\
\text {-91\% of hospitalisations were for RRMS patients } \\
\text {-The mean rates of mortality were } 2.5 \% \text { per year in } \\
\text { RRMS patients } \\
\text {-Mean length of hospitalisation was } 8.9 \text { days } \\
\text {-Average cost per hospitalisation was USD } 358 \\
\text {-Total expenditure with MS inpatient admission was } \\
\text { USD } 651,977 \\
\text {-Relapses were responsible for } 90 \% \text { of admissions in } \\
\text { the population evaluated }\end{array}$ \\
\hline
\end{tabular}


Table 2. Continuation.

\begin{tabular}{|c|c|c|c|c|}
\hline Study & Year & $\begin{array}{l}\text { City/ } \\
\text { Country }\end{array}$ & Outcomes evaluated & Results/Comments \\
\hline $\begin{array}{l}\text { Takemoto, } \\
\text { Takemoto and } \\
\text { Fernandes }\end{array}$ & $2006-2009$ & Brazil & $\begin{array}{l}\text {-Patients under MS treatment in } \\
\text { Brazil from 2006-2009 } \\
\text {-Described treatment used for MS } \\
\text { in } 27 \text { states of Brazil }\end{array}$ & $\begin{array}{l}\text {-2006 with } 3569 \text { patients under treatment } \\
\text {-2009 with } 6099 \text { patients under treatment } \\
\text {-The probability of the use of GA was: } \\
9.5 \% \text { in } 2006,20.1 \% \text { in } 2007,20.7 \% \text { in } 2008 \text { and } 21.3 \% \\
\text { in } 2009 \\
\text {-The probability of use of IFN } 31 \text { a } 22 \text { mcg was } 17.3 \% \text { for } \\
2006 \text { and } 11.4 \% \text { for } 2009 \\
\text {-The probability of use of IFN } \beta 1 \text { a } 44 \text { mcg, IFN } \beta 1 \mathrm{~b} \text { and } \\
\text { IFN } \beta 1 \text { a } 30 \text { mcg, was } 20 \% \text { to } 25 \% \text { across the } \\
4 \text { years }\end{array}$ \\
\hline $\begin{array}{l}\text { Takemoto, } \\
\text { Takemoto and } \\
\text { Fernandes }\end{array}$ & 2006-2009 & Brazil & $\begin{array}{l}\text {-Expenditures with MS treatment in } \\
27 \text { states of Brazil }\end{array}$ & $\begin{array}{l}\text {-MS public expenditures with drugs was USD } \\
\text { 14,011,700 } \\
\text {-MS public expenditure with drugs was USD } \\
122,575,000 \text { in } 2009 \\
\text {-Total investment in MS drugs was USD 360,124,000 } \\
\text { in } 2009\end{array}$ \\
\hline Gonorazky ${ }^{33}$ & 2004 & Argentina & $\begin{array}{l}\text {-Costs of DMD in Argentina per year } \\
\text { for } 2004\end{array}$ & 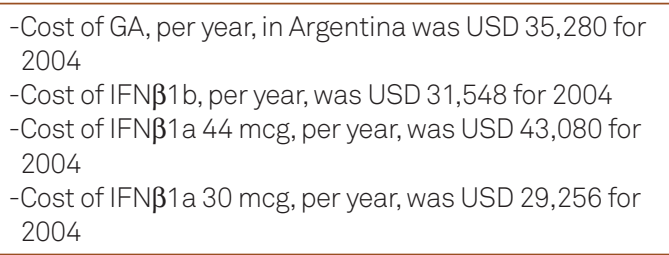 \\
\hline Romero et al. ${ }^{34}$ & $2003-2008$ & Colombia & $\begin{array}{l}\text {-Third payer perspective } \\
\text {-Direct costs (DMD, hospitalisa- } \\
\text { tions, consults, relapses and time } \\
\text { of relapses) in Colombia } \\
\text {-Indirect costs (disability and } \\
\text { caregivers) } \\
\text {-Differential costs by EDSS ( } 0 \text { to } \\
2.5-3,2.5-3 \text { to } 5.5-6,5.5-6 \text { to } \\
7.5-8 \text { and } 7.5-8 \text { to } 9.5)\end{array}$ & $\begin{array}{l}\text { Phase I of the disease (EDSS 0-2.5) } \\
\text {-Direct cost on Phase I of the disease was USD } \\
\text { 1,191,630 (2008), GA 3.1\%, without DMD (USD } \\
\text { 502,384) } \\
\text {-Direct cost with DMD on Phase I was USD 35,964,316 } \\
\text { (2008), COP 92.7\% (USD 15,162,316) } \\
\text {-Indirect cost on Phase I was USD 1,626,516, COP 4.2\% } \\
\text { (USD 685,729) } \\
\text {-Total cost for third payer on Phase I of the disease was } \\
\text { USD 38,782,462, GA (USD 16, 350,570) } \\
\text { Phase II (EDSS 3-5.5) } \\
\text {-Direct cost on Phase II of the disease was USD } \\
\text { 2,714,554 (2008), GA 5.4\%, without DMD (USD } \\
\text { 1,144,443) } \\
\text {-Direct cost with DMD on Phase II was USD 45,862,278 } \\
\text { (2008), GA 90.7\% (USD 19,335,876) } \\
\text {-Indirect cost on Phase II was USD 2,004,372, COP 4\% } \\
\text { (USD 845,031) } \\
\text {-Total cost for third payer on Phase I of the disease was } \\
\text { USD 50,581,204, GA (USD 21, 324,765) } \\
\text { Phase III (EDSS 6-7.5) } \\
\text {-Direct cost on Phase III of the disease was USD } \\
\text { 1,505,988 (2008), COP 4.2\%, without DMD (USD } \\
\text { 634,916) } \\
\text {-Direct cost with DMD on Phase III was USD } \\
\text { 32,686,563 (2008), GA 91.1\% (USD 13,780,500) } \\
\text {-Indirect cost on Phase III was USD 1,706,868, COP } \\
\text { 4.8\% (USD 298,011) } \\
\text {-Total cost for third payer on Phase I of the disease was } \\
\text {-TSD 35,899,419, GA (USD 15,135,000) } \\
\text {-Indirect cost on Phase IV was USD 8,100,000, GA } \\
\text {-Direct cost on Phase IV of the disease was USD } \\
\text { 561,293 (2008), COP 2.7\%, without DMD (USD } \\
\text { 236,638) } \\
\text {-Direct cost with DMD on Phase IV was USD } \\
\text { 12,077,550 (2008), GA 58.2\% (USD 5,091,088) } \\
\text {-Th,843, GA (USD 8,743,370) }\end{array}$ \\
\hline
\end{tabular}

COP:Copolymer; DMD: Disease modifying drug; EDSS: expanded disability status scale; GA: glatiramer acetate; IFN: interferon; MS: multiple sclerosis;

RRMS: relapsing-remitting multiple sclerosis. 


\section{DISCUSSION}

This review allowed us to characterise the research regarding the economics of MS and its treatments in LA. Despite the fact that the methodology for SR of noninterventional research is still in its early stages, valuable information may be extracted from the publications of MS costs in $\mathrm{LA}^{15}$.

In our SR, performed with data obtained from the last 20 years, we found 7 studies meeting our objectives of addressing costs in the region (Tables 1 and 2). Despite the heterogeneity of studies identified, they provide several findings. Relapses are the main cause of admission in MS patients. The mean length of hospitalisation in admitted patients was 8.5 days and the expenditure involved in the admission of MS patients corresponded to $0.53 \%$ of the pharmaceutical expenditure in Brazil. In SA, the cost of hospitalisation seems to be low; we only retrieved an abstract on that data, but no full text was found to confirm this information. This shows a paucity of research in this area. More studies with better quality are needed in order to assess hospitalisations in the MS population. Additionally, no information was retrieved on rehabilitation. Other relevant information obtained relates to the total number of MS patients treated in some areas of Brazil as well as the cost of the specific DMT treatments in Brazil and Argentina. Only one study performed in Argentina suggests that the costs in LA for DMTs appear to be high compared with North America and UK, however, due to the limitations of the design and the data source used to obtain costs in the study, it is difficult to analyse this data ${ }^{33}$. It is also noteworthy that most studies assessing the costs of chronic disabling diseases had clear limitations; hence, the results could not be extrapolated to other latitudes. Finally, a study described both the direct and indirect costs of MS according to the disability of patients, measured by EDSS, in Colombia (Table 2). This was the only study attempting to calculate indirect costs associated with MS and reporting the increased cost associated with advanced stages of MS patients. Additional studies should be conducted to estimate the indirect costs in such patient population.

Previous studies dealing with costs of MS in developed countries demonstrated that the costs of MS are substantial ${ }^{4,13}$. Depending on the perspective taken and the severity of the disease, the cost of MS ranged from USD 6,511 to USD 77,938 per patient per year, in these developed regions ${ }^{13}$. However, this information could not be extrapolated to other regions where costs clearly have variations across countries, due to differences in their approach to data collection, the type of resources included, the assessment of resources, the type of patients involved, the sampling process and the quality of analysis. In addition, costs drivers varied across geographies probably due to the significant differences in the availability of services and use of resources across countries.

European studies demonstrated that with advancement of the disease, the increase of the economic burden was accompanied by changes in the distribution of costs. Thus, costs associated with DMT dominated the overall costs in lower disease-severity levels, while direct nonmedical and indirect costs, such as productivity losses, increased significantly with disease progression ${ }^{38-40}$.

This study represents the first SR of MS costs in LA. Most of the evidence is limited to abstracts; only two full texts addressed this topic. Studies have been performed only in three countries of this region. Most of the research has been conducted in Brazil, focusing on different aspects of costs and benefits. The most comprehensive cost-study was performed in Colombia. The Argentinean study was the only attempt to conduct a cost-effectiveness analysis, but it only included medication costs, thereby offering a limited estimation.

The main limitations of this review include the high risk of bias of the included studies, mainly due to the possibility of under-reporting or selection bias and the heterogeneity of the information provided. Also, only studies published in 1990 and later were included; thus, the data on earlier treatments was unavailable for comparison.

This review addressed the research regarding the economics of MS and its treatments in LA. It also offered a platform to suggest directions for future research. We could address, as desirable future directions, some other endpoints: health-related QoL, health utility research (no data could be retrieved) and additional evidence on adherence and satisfaction with treatment.

Some evidence suggests that costs appear to be high; however, this is based only on two studies, one of which has a cost information source, which is unclear. Cost research should continue on a broader perspective, considering healthcare and societal costs. Economic efficiencies should be explored by targeting therapies to the most appropriate patients ${ }^{12}$. Finally, this type of SR should be updated as more evidence becomes available.

In summary, there is much to be learnt about MS costs in LA, particularly in relationship to the longitudinal course of severity of the disease. Future research performed in each country, considering the economic outcomes of MS, will expand the knowledge and management of MS in that particular region. There is also a need to develop guidelines to conduct studies on costs of illness in MS in order to improve their consistency, reliability and usefulness in decision making. 
1. Simmons RD. Life issues in multiple sclerosis. Nat Rev Neurol 2010;6:603-610.

2. Lublin FD, Reingold SC. Defining the clinical course of multiple sclerosis: results of an international survey. National Multiple Sclerosis Society (USA) Advisory Committee on Clinical Trials of New Agents in Multiple Sclerosis. Neurology 1996;46:907-911.

3. Patwardhan MB, Matchar DB, Samsa GP, McCrory DC, Williams RG, Li TT. Cost of multiple sclerosis by level of disability: a review of literature. Mult Scler 2005;11:232-239.

4. Kobelt G, Pugliatti M. Cost of multiple sclerosis in Europe. Eur J Neurol 2005;12(Suppl 1):S63-S67.

5. Johnson KP, Brooks BR, Cohen JA, et al. Copolymer 1 reduces relapse rate and improves disability in relapsing-remitting multiple sclerosis: results of a phase III multicenter, double-blind placebo-controlled trial. The Copolymer 1 Multiple Sclerosis Study Group. Neurology 1995;45:1268-1276.

6. Jacobs LD, Cookfair DL, Rudick RA, et al. Intramuscular interferon beta-1a for disease progression in relapsing multiple sclerosis. The Multiple Sclerosis Collaborative Research Group (MSCRG). Ann Neurol 1996;39:285-294.

7. Randomised double-blind placebo-controlled study of interferon beta-1a in relapsing/remitting multiple sclerosis. PRISMS (Prevention of Relapses and Disability by Interferon beta-1a Subcutaneously in Multiple Sclerosis) Study Group. Lancet 1998;352:1498-1504.

8. Interferon beta-1b is effective in relapsing-remitting multiple sclerosis. I. Clinical results of a multicenter, randomized, doubleblind, placebo-controlled trial. The IFNB Multiple Sclerosis Study Group. Neurology 1993;43:655-661.

9. Polman $\mathrm{CH}, \mathrm{O}$ 'Connor PW, Havrdova E, et al. A randomized, placebocontrolled trial of natalizumab for relapsing multiple sclerosis. N Engl J Med 2006;354:899-910.

10. Kappos L, Radue EW, O'Connor P, et al. A placebo-controlled trial of oral fingolimod in relapsing multiple sclerosis. N Engl J Med 2010;362:387-401.

11. Whetten-Goldstein K, Sloan FA, Goldstein LB, Kulas ED. A comprehensive assessment of the cost of multiple sclerosis in the United States. Mult Scler 1998;4:419-425.

12. Noyes K, Bajorska A, Chappel A, et al. Cost-effectiveness of diseasemodifying therapy for multiple sclerosis: a population-based study. Neurology 2011;77:355-363.

13. Sharac J, McCrone P, Sabes-Figuera R. Pharmacoeconomic considerations in the treatment of multiple sclerosis. Drugs 2010;70:1677-1691.

14. Kurtzke JF. MS epidemiology worldwide. One view of current status. Acta Neurol Scand Suppl 1995;161:S23-S33.

15. Cristiano E, Patrucco L, Rojas Jl. A systematic review of the epidemiology of multiple sclerosis in South America. Eur $\mathrm{J}$ Neurol 2008;15:1273-1278.

16. Pugliatti M, Sotgiu S, Rosati G. The worldwide prevalence of multiple sclerosis. Clin Neurol Neurosurg 2002;104:182-191.

17. Rosati G, Aiello I, Pirastru MI, et al. Epidemiology of multiple sclerosis in Northwestern Sardinia: further evidence for higher frequency in Sardinians compared to other Italians. Neuroepidemiology 1996;15:10-19.

18. Kurtzke JF. Epidemiology of multiple sclerosis. Does this really point toward an etiology? Lectio Doctoralis. Neurol Sci 2000;21:383-403.

19. Rosati G. The prevalence of multiple sclerosis in the world: an update. Neurol Sci 2001;22:117-139.

20. Correale J. Epidemiology of MS in Latin America. Multiple Sclerosis 2009;15:15.
21. Cristiano E, Patrucco L, Soriano E, Videla G, Hares D, Bauzo T. Incidence and prevalence of Multiple Sclerosis in an HMO in Argentina. Mult Scl 2002;8:36.

22. Barahona J, Montero A, Flores A. Multiple sclerosis in Chile. Arq Neuropsiquiatr 2004;62:11.

23. Callegaro D, Goldbaum M, Morais L, et al. The prevalence of multiple sclerosis in the city of Sao Paulo, Brazil, 1997. Acta Neurol Scand 2001;104:208-213.

24. Corona T, Roman GC. Multiple sclerosis in Latin America. Neuroepidemiology 2006;26:1-3.

25. Pugliatti M, Riise T, Sotgiu MA, et al. Increasing incidence of multiple sclerosis in the province of Sassari, northern Sardinia. Neuroepidemiology 2005;25:129-134.

26. Stroup DF, Berlin JA, Morton SC, et al. Meta-analysis of observational studies in epidemiology: a proposal for reporting. Meta-analysis of observational studies in epidemiology (MOOSE) group. JAMA 2000;283:2008-2012.

27. Liberati A, Altman DG, Tetzlaff J, et al. The PRISMA statement for reporting systematic reviews and meta-analyses of studies that evaluate health care interventions: explanation and elaboration. PLoS Med 2009;6:e1000100.

28. von Elm E, Altman DG, Egger M, Pocock SJ, Gotzsche PC, Vandenbroucke JP. The Strengthening the Reporting of Observational Studies in Epidemiology (STROBE) statement: guidelines for reporting observational studies. Lancet 2007;370:1453-1457.

29. Fowkes FG, Fulton PM. Critical appraisal of published research: introductory guidelines. BMJ 1991;302:1136-1140.

30. Takemoto MMS, Takemoto ML, Fernandes RA, et al. Medication treatment patterns for multiple sclerosis patients in the Brazilian public health care system. Value Health. 2011;14:212-213.

31. Takemoto MMS, Takemoto ML, Fernandes RA, et al. Temporal trends and geographic discrepancies in public expenditures with multiple sclerosis drug treatment in Brazil. Value Health. 2011;14:212.

32. Takemoto MMS, Takemoto ML, Fernandes RA, et al. Inpatient health resource utilization among multiple sclerosis patients in the Brazilian public health care system. Value Health. 2011;14:212.

33. Gonorazky S. Tratamiento de la esclerosis múltiple con los interferones beta y el acetato de glatiramer: evaluación del costo relacionado a la eficacia en Argentina, Estados Unidos y Gran Bretaña. Rev Neurol Argentina. 2004;29:24-29.

34. Romero M, Arango C, Alvis N, Suarez JC, Duque A. The cost of treatment of multiple sclerosis in Colombia. Value Health 2011;14:48-50.

35. Bueno RLP, Godoy MR, Suzuki C. Brazilian national guideline for multiple sclerosis (MS): an exploratory study about the impact of the patient's adherence in the treatment costs. Value Health. 2009;12:197-198.

36. Ferreira da Silva AL, Filkelsztejn A, Ribeiro R, Polanczyk CA. Value of budget impact analysis based on epidemiologic data: insights from multiple sclerosis in Sao Paulo, Brazil. Value Health 2010;13:388.

37. Kurtzke JF. Rating neurologic impairment in multiple sclerosis: an expanded disability status scale (EDSS). Neurology 1983;33: 1444-1452.

38. Kobelt G, Berg J, Lindgren P, Gerfin A, Lutz J. Costs and quality of life of multiple sclerosis in Switzerland. Eur $J$ Health Econ 2006;7(Suppl 2):S86-S95.

39. Kobelt $\mathrm{G}$. Costs and quality of life for patients with multiple sclerosis in Belgium. Eur J Health Econ 2006;7(Suppl 2):S24-S33.

40. Henriksson F, Frederksson F, Materman T, Jonsson B. Cost and quality of life and disease severity in multiple sclerosis: a cross-sectional study in Sweden. Eur J Neurol 2001;8:27-35. 